\title{
The Association between Iron-deficiency Anemia and Adverse Pregnancy Outcomes: A Retrospective Report from Pakistan
}

Tuba Mahmood ${ }^{1}$, Atique Ur Rehman ${ }^{2}$, Gantuya Tserenpil ${ }^{3}$, Faiza Siddiqui ${ }^{4}$, Mehak Ahmed ${ }^{5}$, Fatima Siraj $^{6}$, Besham Kumar ${ }^{7}$

1. Cardiology, Quaid-e-Azam Medical College, Bahawalpur, PAK 2. Internal Medicine, Quaid-e-Azam Medical College, Bahawalpur, PAK 3. Internal Medicine, Mongolian National University of Medical Sciences, Ulaanbaatar, MNG 4. Anatomy, Liaquat College of Medicine and Dentistry, Karachi, PAK 5. Medicine, Liaquat College of Medicine and Dentistry, Karachi, PAK 6. Miscellaneous, Liaquat College of Medicine and Dentistry, Karachi, PAK 7. Internal Medicine, Jinnah Postgraduate Medical Center, Karachi, PAK

Corresponding author: Besham Kumar, beshamkumar916@gmail.com

\section{Abstract \\ Background}

Anemia is one of the most common conditions that affect pregnancies, with dietary iron deficiency being its most common cause. Maternal anemia has been associated with increased risks of both maternal and neonatal adverse outcomes. This study aimed to analyze the maternal and neonatal outcomes in women with third-trimester anemia.

\section{Methods}

This was a retrospective report from a Pakistani public hospital. It included data records of the childbirths in the hospital, with at least one record that documented the hemoglobin $(\mathrm{Hb})$ level in women in the first or second trimester and one in the third trimester. The duration of the study was from January 1, 2019 to June 30, 2019. Women with $\mathrm{Hb}$ level of $<10 \mathrm{mg} / \mathrm{dL}$ in the third trimester were categorized as anemic, and those with $\mathrm{Hb}$ level of $>10 \mathrm{mg} / \mathrm{dL}$ were categorized as non-anemic. Pregnancy outcomes were assessed for both mothers and babies. All data were processed through SPSS version 21.0 for Windows (IBM Corp., Armonk, $\mathrm{NY})$.

\section{Results}

The study evaluated 235 (37.8\%) anemic and 387 (62.2\%) non-anemic women. Adverse maternal outcomes were compared between the two groups. In anemic women, gestational hypertension ( $56 \%$ vs. $27 \%$; p: $<0.0001$ ), preeclampsia ( $65 \%$ vs. $25 \%$; p: $<0.0001$ ), antepartum hemorrhage ( $32 \%$ vs. $19 \%$; p: $=0.0001$ ), postpartum hemorrhage ( $79 \%$ vs. $28 \%$; p: $<0.0001)$, transfusions ( $94 \%$ vs. $5 \%$; p: $<0.0001)$,

prolonged/obstructed labor ( $49 \%$ vs. $20 \%$; p: $<0.000)$, urgent induction of labor $(24 \%$ vs. $2 \%$; p: $<0.0001)$, and

Received 09/18/2019

urgent caesarean section (CS) ( $45 \%$ vs. $29 \%$; p: 0.0001) were significantly more common as compared to nonanemic women. Adverse neonatal outcomes such as low birth weight (LBW) (59\% vs. 29\%; p: <0.0001), small-for-gestational-age (SGA) (73\% vs. $23 \%$; p: <0.0001), preterm delivery (39\% vs. $15 \%$; p: <0.0001), stillbirth ( $8 \%$ vs. $3 \%$; p: 0.01 ), and early neonatal death ( $9 \%$ vs. $2 \%$; p: 0.000$)$ were associated more with anemia. There was no report of maternal mortality in either group.

\section{Conclusion:}

Anemia in the third trimester of pregnancy is associated with adverse maternal and neonatal outcomes including neonatal death. Efforts are required to ensure adequate maternal nutritional status in order to prevent poor outcomes.

Categories: Obstetrics/Gynecology, Pediatrics, Preventive Medicine

Keywords: antenatal anemia, maternal anemia, adverse pregnancy outcomes, neonatal outcomes, anemia in pregnancy

\section{Introduction}

Anemia is among the most common conditions that affect pregnancies. Anemia in pregnancy has a varied incidence and etiology depending on the geographic location [1]. The incidence of anemia has been as high as $35-75 \%$ in developing countries compared with only $19 \%$ in developed countries [2].

According to guidelines published in the UK in collaboration with the British Society for Haematology (BSH), Obstetric Haematology Group (BSH OHG), and British Committee for Standards in Haematology (BCSH), anemia in pregnancy is defined as the condition where serum hemoglobin $(\mathrm{Hb})$ level is $<11.0 \mathrm{mg} / \mathrm{dl}$ in the 
first trimester, $<10.5 \mathrm{mg} / \mathrm{dl}$ in the second and third trimesters, and $<10.0 \mathrm{mg} / \mathrm{dl}$ in the postpartum period [3].

There are several pathologies that cause anemia in pregnancy, including acute and chronic infections, disorders of hemoglobin synthesis, and nutritional deficiencies such as deficiency of vitamin B12, folic acid, and iron. Dietary iron deficiency is the most common cause of anemia in pregnancy [4]. Irrespective of the etiology, maternal anemia has been associated with increased risks of both maternal and neonatal adverse outcomes. In a study conducted in Israel, maternal anemia was found to increase the risk of cesarean sections (CS) and the need for blood transfusions. The same study also observed that the neonates of anemic women had an increased risk of a low APGAR score [5]. Other adverse outcomes include preterm delivery [6], small-for-gestational-age (SGA) (weight below the 10th percentile for the gestational age) [7], postpartum hemorrhage (PPH), and preeclampsia [8,9]. Even though the trends in Pakistani neonates have been studied from several angles [10-12], little attention has been given to maternal outcomes [9]. Hence, this study was designed to analyze the maternal and neonatal outcomes in women with third-trimester anemia.

\section{Materials And Methods}

This was a review of a historical cohort of all patients delivering in the obstetrics and gynecology department of a tertiary care hospital in Pakistan from January 1, 2019 to June 30, 2019. This study was approved by the institutional review board. Only those data records that had at least one record of hemoglobin $(\mathrm{Hb})$ level in the first or second trimester and one in the third trimester were included.

A semi-structured proforma was constructed to record maternal and neonatal information. Patients were divided into two groups based on their $\mathrm{Hb}$ level in the third trimester. Women with $\mathrm{Hb}$ level of $<10 \mathrm{mg} / \mathrm{dL}$ were categorized as anemic, and those with $\mathrm{Hb}$ level of $>10 \mathrm{mg} / \mathrm{dL}$ were categorized as non-anemic [3]. Demographic characteristics including age, body weight, height, smoking status, and parity were recorded. Clinical characteristics including the history of antenatal visits and outcomes of previous pregnancies, iron supplementation status, and $\mathrm{Hb}$ level in the first and/or second trimester of current pregnancy were recorded. Pregnancy outcomes were assessed for both the mothers and babies. Maternal outcomes included in the study were gestational hypertension, preeclampsia, eclampsia, antenatal hemorrhage (any bleeding from the genital tract at $24+0$ weeks of gestation till before delivery), postpartum hemorrhage ( $>500 \mathrm{ml}$ of blood loss during or within 24 hours of delivery), obstruction of labor (OL)/prolonged labor (PL), induction of labor (IOL), blood transfusions, emergency CS/laparotomy, and maternal mortality. Fetal outcomes included fetal distress, low birth weight (LBW) (less than 2,500 grams), SGA, prematurity (childbirth before 37+0 weeks of gestation), neonatal intensive care unit (NICU) admission, stillbirth, and early neonatal death.

Statistical analysis was completed through SPSS version 21.0 for Windows (IBM Corp., Armonk, NY). Categorical data were presented as frequencies and percentages. Continuous data were presented as mean and standard deviation (SD). A chi-square test was performed to analyze the correlation between categorical variables. A p-value of $\leqslant 0.05$ was considered significant.

\section{Results}

There were 622 records included in the analysis. The mean age of the women was $29.4( \pm 12.5)$ years. The mean BMI of the women was $29.3( \pm 6.4) \mathrm{kg} / \mathrm{m}^{2}$, and their mean parity was $5( \pm 3)$. There were $235(37.8 \%)$ women who were anemic in their third trimester and 387 (62.2\%) who were non-anemic. Their baseline characteristics were compared. It showed that anemic women were younger in age, less likely to have a normal body weight, more likely to be active as well as passive smokers, and more likely to be primiparous (Table 1). 


\section{Cureus}

\begin{tabular}{|c|c|c|c|}
\hline Baseline characteristics & Anemic $(n=235 ; 37.8 \%)$ & Non-anemic $(n=387 ; 62.2 \%)$ & P-value \\
\hline \multicolumn{4}{|l|}{ Maternal age, years } \\
\hline Less than 20 & $93(39.5 \%)$ & $102(26.3 \%)$ & \multirow{3}{*}{0.002} \\
\hline $20-30$ & $88(37.4 \%)$ & $172(44.4 \%)$ & \\
\hline More than 30 & $54(23.0 \%)$ & $113(29.2 \%)$ & \\
\hline \multicolumn{4}{|l|}{$\mathrm{BMI}, \mathrm{kg} / \mathrm{m}^{2}$} \\
\hline Underweight (<18.5 kg) & $123(52.3 \%)$ & $89(22.9 \%)$ & \multirow{4}{*}{$<0.0001$} \\
\hline Normal (18.5-24.9 kg) & $37(15.7 \%)$ & $193(49.8 \%)$ & \\
\hline Overweight (25-29.9 kg) & $43(18.3 \%)$ & $78(20.2 \%)$ & \\
\hline Obese (>30 kg) & $32(13.6 \%)$ & $27(6.9 \%)$ & \\
\hline \multicolumn{4}{|l|}{ Smoking status } \\
\hline Active smoker & $53(22.5 \%)$ & 64 (16.5\%) & \multirow{4}{*}{$<0.0001$} \\
\hline Passive smoker & $201(85.5 \%)$ & $156(40.3 \%)$ & \\
\hline Ex-smoker & $19(8.1 \%)$ & $54(13.9 \%)$ & \\
\hline Non-smoker & $163(69.4 \%)$ & $269(69.5 \%)$ & \\
\hline \multicolumn{4}{|l|}{ Parity } \\
\hline 0 & $102(43.4 \%)$ & $95(24.5 \%)$ & \multirow{4}{*}{$<0.0001$} \\
\hline $1-3$ & $56(23.8 \%)$ & $126(32.5 \%)$ & \\
\hline 4-6 & 14 (5.9\%) & 75 (19.4\%) & \\
\hline More than 7 & $63(26.8 \%)$ & $91(23.5 \%)$ & \\
\hline
\end{tabular}

\section{TABLE 1: Comparison of baseline demographic characteristics of the anemic and non-anemic}

study population

In the anemic group, $52 \%$ had been anemic since their first trimester and the percentage increased to $66 \%$ in the second trimester as compared to $30 \%$ in the first and $20 \%$ in the second trimester in the non-anemic group. The mean $\mathrm{Hb}$ level of the anemic group was $6.8( \pm 2.5) \mathrm{mg} / \mathrm{dL}$ in the first trimester, $7.3( \pm 1.8) \mathrm{mg} / \mathrm{dL}$ in the second, and $7.2( \pm 1.3) \mathrm{mg} / \mathrm{dL}$ in the third trimester. The mean $\mathrm{Hb}$ level of the non-anemic group was 8.1 $( \pm 2.7) \mathrm{mg} / \mathrm{dL}$ in the first trimester, $8.8( \pm 2.9) \mathrm{mg} / \mathrm{dL}$ in the second, and $8.9( \pm 1.9) \mathrm{mg} / \mathrm{dL}$ in the third trimester. A comparison of the clinical characteristics of both groups was performed, which showed that anemic women had significantly lower $\mathrm{Hb}$ values in first and second trimesters, poor compliance to antenatal visits, lower frequency of iron supplementation, and more frequent treatment for iron deficiency (Table 2). 


\section{Cureus}

\begin{tabular}{|c|c|c|c|}
\hline Clinical characteristics & Anemic $(n=235 ; 37.8 \%)$ & Non-anemic $(n=387 ; 62.2 \%)$ & P-value \\
\hline \multicolumn{4}{|c|}{ Hemoglobin level in the first trimester, $\mathrm{g} / \mathrm{dL}$} \\
\hline Less than 8 & $123(52.3 \%)$ & $115(29.7 \%)$ & \multirow{3}{*}{$<0.0001$} \\
\hline 8-10 & $82(34.8 \%)$ & $145(37.5 \%)$ & \\
\hline More than 10 & $9(3.8 \%)$ & $100(25.8 \%)$ & \\
\hline Missing & $21(8.9 \%)$ & $27(6.9 \%)$ & \\
\hline \multicolumn{4}{|c|}{ Hemoglobin level in the second trimester, $\mathrm{g} / \mathrm{dL}$} \\
\hline Less than 8 & $155(65.9 \%)$ & $78(20.2 \%)$ & \multirow{4}{*}{ Not applicable } \\
\hline 8-10 & $44(18.7 \%)$ & $203(52.4 \%)$ & \\
\hline More than 10 & $0(0 \%)$ & $99(25.5 \%)$ & \\
\hline Missing & $36(15.3 \%)$ & $7(1.8 \%)$ & \\
\hline \multicolumn{4}{|l|}{ Iron supplements taken } \\
\hline In current pregnancy & $68(28.9 \%)$ & $128(33.1 \%)$ & \multirow{3}{*}{$<0.0001$} \\
\hline In previous pregnancies & $103(43.8 \%)$ & $235(60.7 \%)$ & \\
\hline Never during pregnancy & $64(27.2 \%)$ & $24(6.2 \%)$ & \\
\hline \multicolumn{4}{|l|}{ Intravenous iron replacement } \\
\hline In current pregnancy & $104(44.3 \%)$ & $21(5.4 \%)$ & \multirow{3}{*}{$<0.0001$} \\
\hline In previous pregnancies & $115(48.9 \%)$ & $66(17.1 \%)$ & \\
\hline Never during pregnancy & $29(12.3 \%)$ & $300(77.5 \%)$ & \\
\hline \multicolumn{4}{|c|}{ Antenatal visits in previous pregnancies (not valid for primigravida) } \\
\hline None & $53 / 133(39.8 \%)$ & 33/292 (11.3\%) & \multirow{3}{*}{$<0.0001$} \\
\hline One only & $58 / 133(43.6 \%)$ & 101/292 (34.5\%) & \\
\hline More than one & 22/133 (16.5\%) & 158/292 (54.1\%) & \\
\hline \multicolumn{4}{|c|}{ Outcome of previous pregnancies (not valid for primigravida) } \\
\hline Alive and healthy & $103 / 133(77.4 \%)$ & $279 / 292(95.5 \%)$ & \multirow{3}{*}{$<0.0001$} \\
\hline Abortion/fetal death/stillbirth & 21/133 (15.8\%) & 10/292 (3.4\%) & \\
\hline Neonatal/early-childhood death & 9/133 (6.8\%) & $3 / 292(1.0 \%)$ & \\
\hline
\end{tabular}

\section{TABLE 2: Comparison of clinical characteristics of the anemic and non-anemic study population}

Maternal and neonatal outcomes were compared. In the anemic women group, pregnancy-related complications including gestational hypertension, preeclampsia, eclampsia, antepartum, and postpartum hemorrhage were more common. There was a higher frequency of obstructed/prolonged labor and fetal distress leading to induction and/or emergency CS/laparotomy in the anemic group. The neonatal outcome was also poor in the anemic group. There were no maternal mortalities in our study. There were $29(4.7 \%)$ neonatal deaths, out of which 21 (3.4\%) pertained to anemic mothers (Table 3). 


\section{Cureus}

\begin{tabular}{|c|c|c|c|}
\hline Pregnancy outcomes & $\begin{array}{l}\text { Anemic ( } n=235 ; \\
37.8 \%)\end{array}$ & $\begin{array}{l}\text { Non-anemic ( } \mathrm{n}=387 \text {; } \\
62.2 \%)\end{array}$ & P-value \\
\hline Gestational hypertension & $131(55.7 \%)$ & $103(26.6 \%)$ & $<0.000$ \\
\hline Preeclampsia & $153(65.1 \%)$ & $98(25.3 \%)$ & $<0.000$ \\
\hline Eclampsia & $5(2.1 \%)$ & $0(0 \%)$ & $\begin{array}{l}\text { Not } \\
\text { applicable }\end{array}$ \\
\hline Antepartum hemorrhage & $76(32.3 \%)$ & $73(18.8 \%)$ & 0.0001 \\
\hline Postpartum hemorrhage (>500 ml) & $185(78.7 \%)$ & $107(27.6 \%)$ & $<0.000$ \\
\hline Major obstetric hemorrhage (>2,000 ml) & $58(24.7 \%)$ & $12(3.1 \%)$ & $<0.000$ \\
\hline Need for blood transfusion during/within 24 hours of delivery & $221(94.0 \%)$ & $19(4.9 \%)$ & $<0.000$ \\
\hline Prolonged/obstructed labor & $115(48.9 \%)$ & $76(19.6 \%)$ & $<0.000$ \\
\hline Need of urgent laparotomy due to uncontrollable bleeding & $12(5.1 \%)$ & $0(0 \%)$ & $\begin{array}{l}\text { Not } \\
\text { applicable }\end{array}$ \\
\hline Need of urgent induction of labor due to maternal/fetal distress & $56(23.8 \%)$ & $8(2.1 \%)$ & $<0.000$ \\
\hline $\begin{array}{l}\text { Need of urgent caesarean section due to fetal distress/prolonged labor/failure } \\
\text { of induction }\end{array}$ & $105(44.6 \%)$ & $113(29.2 \%)$ & 0.0001 \\
\hline Low birth weight $(<2,500 \mathrm{~g})$ & $138(58.7 \%)$ & $114(29.5 \%)$ & $<0.000$ \\
\hline Very low birth weight $(<1,500 \mathrm{~g})$ & $78(33.2 \%)$ & $13(3.3 \%)$ & $<0.000$ \\
\hline Small-for-gestational-age & $173(73.6 \%)$ & $89(22.9 \%)$ & $<0.000$ \\
\hline Preterm delivery & $93(39.5 \%)$ & $58(14.9 \%)$ & $<0.000$ \\
\hline Stillbirth & $18(7.6 \%)$ & $12(3.1 \%)$ & 0.01 \\
\hline Early neonatal death (within 24 hours) & $21(8.9 \%)$ & $8(2.1 \%)$ & 0.000 \\
\hline NICU admission & $135(57.4 \%)$ & $94(24.3 \%)$ & $<0.000$ \\
\hline
\end{tabular}

TABLE 3: Comparison of maternal and neonatal outcomes of the anemic and non-anemic study population

NICU: Neonatal intensive care unit

\section{Discussion}

Maternal anemia is a common problem encountered by gynecologists and obstetricians worldwide, especially in developing countries. In this study, we found an association between anemia in pregnancy and adverse maternal and neonatal outcomes. While this study throws light on the issue in a developing country, its results cannot be generalized as it was based on cases at a single facility. It lacks demographic diversity, and there is a high probability of missing/incomplete data due to its retrospective nature.

Other studies have shown similar results to ours. Nair et al. studied a large retrospective cohort from India in which $35 \%$ of pregnant women had moderate-to-severe anemia. This study reported that anemic women had a nine times higher risk of PPH. For anemic women who underwent an IOL, the risk increased 17-fold; and for anemic women with infections, it increased 19-fold. Adverse neonatal outcomes associated with anemia were LBW, SGA, and perinatal death [13]. SGA, LBW, and preterm delivery have been reported in other studies from India as well $[9,14]$. Parks et al. also reported a significant association between severe anemia and PPH and neonatal mortality, but no connection between severe anemia and maternal mortality was observed [9].

The trends from other developing countries such as Sudan, Tanzania, and Bangladesh have not been very different either [13-20]. Neonatal adverse outcomes associated with maternal anemia in these countries include low placental weight, LBW/very LBW, poor APGAR score, SGA, birth asphyxia, fetal anemia, stillbirth, and preterm delivery [13-20]. Maternal adverse outcomes reported in the literature include preeclampsia, PPH, CS delivery, and infections $[19,9,21]$. 
Although the incidence of nutritional anemia in pregnancy is low and is in a further decline in developed countries, it is still associated with poor maternal outcomes [22]. In a Scottish retrospective cohort, maternal anemia reportedly increased the risk of antepartum hemorrhage, severe obstetric hemorrhage, the need for blood transfusion, postpartum infection, and maternal death [22]. Among Finnish multiparous women, antenatal anemia was associated with preterm delivery, SGA, and NICU admission [23]. Demuth et al. reported that less than half of the German women diagnosed with iron-deficiency anemia were taking a therapeutic dose of supplemental iron during their pregnancy [24].

Currently, the management of labor and delivery in women with moderate-to-severe anemia is not governed by any standard guidelines $[25,26]$. The frequency of anemia in the last trimester is on the higher side (38\%) as reported in this study. It carries a high risk of poor maternal and fetal outcomes. There is an urgent need to find more evidence and design high-quality protocols on adequate management of women with moderate-to-severe anemia during labor, delivery, and the postpartum period. We believe this study has highlighted the incidence and consequences of antenatal anemia among Pakistani women. There is evidently a pressing need to address maternal nutrition and the general health of women of childbearing age. The need for more interventional studies that can include larger samples at an epidemiological level and anemias of various etiologies cannot be overstated. Studies must be undertaken to assess the value of treating anemia as an independent risk factor in predicting the outcome of pregnancy. There should be an increased focus on improving awareness about the positive impact of adequate micronutrient replenishment on the health of the mother as well as the newborn.

\section{Conclusions}

Maternal anemia is associated with adverse maternal and neonatal outcomes. It is important to identify women at risk and ensure that sufficient and timely care is provided. Awareness campaigns must be conducted to educate women about the need to take care of their health and well-being during pregnancy in order for them to have healthy babies. The focus should be placed on proper and adequate maternal nutrition, and women must be urged to seek antenatal care on a regular basis. Appropriate antenatal care will help reduce adverse preventable outcomes such as third-trimester anemia. Awareness campaigns should not be confined to pregnant women, and all women of childbearing age must be educated about the importance of adequate maternal nutrition.

\section{Additional Information \\ Disclosures}

Human subjects: Consent was obtained by all participants in this study. Ethical Review Committee, Quaid e Azam Medical College issued approval ERC-QAMC-2019-03. Animal subjects: All authors have confirmed that this study did not involve animal subjects or tissue. Conflicts of interest: In compliance with the ICMJE uniform disclosure form, all authors declare the following: Payment/services info: All authors have declared that no financial support was received from any organization for the submitted work. Financial relationships: All authors have declared that they have no financial relationships at present or within the previous three years with any organizations that might have an interest in the submitted work. Other relationships: All authors have declared that there are no other relationships or activities that could appear to have influenced the submitted work.

\section{References}

1. Bakacak M, Avci F, Ercan O, et al.: The effect of maternal hemoglobin concentration on fetal birth weight according to trimesters. J Matern Fetal Neonatal Med. 2015, 28:2106-10. 10.3109/14767058.2014.979149

2. Öztürk M, Öztürk Ö, Ulubay M, et al.: Anemia prevalence at the time of pregnancy detection. Turkish J Obstet Gynecol. 2017, 14:176-180. 10.4274/tjod.06337

3. Pavord S, Myers B, Robinson S, Allard S, Strong J, Oppenheimer C: British Committee for Standards in Haematology. UK guidelines on the management of iron deficiency in pregnancy. Br J Hematol. 2012, 156:588-600. 10.1111/j.1365-2141.2011.09012.x

4. de Sá SA, Willner E, Duraes Pereira TA, de Souza VR, Teles Boaventura G, Blondet de Azeredo V: Anemia in pregnancy: impact on weight and in the development of anemia in newborn. Nutr Hosp. 2015, 32:2071-9. 10.3305/nh.2015.32.5.9186

5. Drukker L, Hants Y, Farkash R, Ruchlemer R, Samueloff A, Grisaru-Granovsky S: Iron deficiency anemia at admission for labor and delivery is associated with an increased risk for cesarean section and adverse maternal and neonatal outcomes. Transfusion. 2015, 55:2799-806. 10.1111/trf.13252

6. Ronkainen J, Lowry E, Heiskala A, et al.: Maternal hemoglobin associates with preterm delivery and small for gestational age in two Finnish birth cohorts. Eur J Obstet Gynecol Reprod Biol. 2019, 238:44-8. 10.1016/j.ejogrb.2019.04.045

7. Badfar G, Shohani M, Soleymani A, Azami M: Maternal anemia during pregnancy and small for gestational age: a systematic review and meta-analysis. J Matern Fetal Neonatal Med. 2019, 32:1728-34. 10.1080/14767058.2017.1411477

8. Young MF, Oaks BM, Tandon S, Martorell R, Dewey KG, Wendt AS: Maternal hemoglobin concentrations across pregnancy and maternal and child health: a systematic review and meta-analysis. Ann N Y Acad Sci. 2019, 450:47-68. 10.1111/nyas.14093

9. Parks S, Hoffman MK, Goudar SS, et al.: Maternal anaemia and maternal, fetal, and neonatal outcomes in a 
prospective cohort study in India and Pakistan. BJOG. 2019, 126:737-43. 10.1111/1471-0528.15585

10. Nisar YB, Dibley MJ: Iron/folic acid supplementation during pregnancy prevents neonatal and under-five mortality in Pakistan: propensity score matched sample from two Pakistan demographic and health surveys. Glob Health Action. 2016, 9:29621. 10.3402/gha.v9.29621

11. Lone FW, Qureshi RN, Emmanuel F: Maternal anaemia and its impact on perinatal outcome in a tertiary care hospital in Pakistan. East Mediterr Health J. 2004, 10:801-7.

12. Bano T, Nazar B, Tahir MR: APGAR score of neonates born to anemic mothers versus non-anemic mothers . JIMDC. 2018, 7:246-49. 10.35787/jimdc.v7i4.252

13. Nair M, Choudhury MK, Choudhury SS, Kakoty SD, Sarma UC, Webster P, Knight M: Association between maternal anaemia and pregnancy outcomes: a cohort study in Assam, India. BMJ Glob Health. 2016, 1:Accessed: October 7, 2019: 10.1136/bmigh-2015-000026

14. Bora R, Sable C, Wolfson J, Boro K, Rao R: Prevalence of anemia in pregnant women and its effect on neonatal outcomes in Northeast India. J Matern Fetal Neonatal Med. 2014, 27:887-91. 10.3109/14767058.2013.845161

15. Akhter S, Momen MA, Rahman MM, Parveen T, Karim RK: Effect of maternal anemia on fetal outcome . Mymensingh Medical J. 2010, 19:391-8.

16. Mahamuda B, Tanira S, Feroza W, Perven HA, Shamim A: Effects of maternal anaemia on neonatal outcome a study done in the specialized urban hospital set up in Bangladesh. Bangladesh J Med Sci. 2011, 10:177-180. 10.3329/bjms.v10i3.8361

17. Elhassan EM, Abbaker AO, Haggaz AD, Abubaker MS, Adam I: Anaemia and low birth weight in Medani Hospital, Sudan. BMC Res Notes. 2010, 3:181. Accessed: October 7, 2019: 10.1186/1756-0500-3-181

18. Adam I, Elhassan EM, Haggaz AE, Ali AA, Adam GK: A perspective of the epidemiology of malaria and anaemia and their impact on maternal and perinatal outcomes in Sudan. J Infect Dev Ctries. 2011, 5:83-7.

19. Ali AA, Rayis DA, Abdallah TM, Elbashir MI, Adam I: Severe anaemia is associated with a higher risk for preeclampsia and poor perinatal outcomes in Kassala hospital, eastern Sudan. BMC Res Notes. 2011, 4:311. Accessed: October 7, 2019: 10.1186/1756-0500-4-311

20. Msuya SE, Hussein TH, Uriyo J, Sam NE, Stray-Pedersen B: Anaemia among pregnant women in northern Tanzania: prevalence, risk factors and effect on perinatal outcomes. Tanzan J Health Res. 2011, 13:33-9.

21. Youssry MA, Radwan AM, Gebreel MA, Patel TA: Prevalence of maternal anemia in pregnancy: the effect of maternal hemoglobin level on pregnancy and neonatal outcome. Open J Obstet Gynecol. 2018, 8:676-87. 10.4236/ojog.2018.87072

22. Rukuni R, Bhattacharya S, Murphy MF, Roberts D, Stanworth SJ, Knight M: Maternal and neonatal outcomes of antenatal anemia in a Scottish population: a retrospective cohort study. Acta Obstet Gynecol Scand. 2016, 95:555-64. 10.1111/aogs.12862

23. Räisänen S, Kancherla V, Gissler M, Kramer MR, Heinonen S: Adverse perinatal outcomes associated with moderate or severe maternal anaemia based on parity in Finland during 2006-10. Pediatr Perinat Epidemiol. 2014, 28:372-80. 10.1111/ppe.12134

24. Demuth IR, Martin A, Weissenborn A: Iron supplementation during pregnancy - a cross-sectional study undertaken in four German states. BMC Pregnancy Childbirth. 2018, 18:491. Accessed: October 7, 2019: 10.1186/s12884-018-2130-5

25. World Health Organization: Iron deficiency anaemia: assessment, prevention and control, a guide for programme managers. WHO, Geneva; 2001.

26. World Health Organization, Dept. of Reproductive Health and Research: WHO recommendations for induction of labour. WHO, Geneva; 2011. 